\title{
LA TRANSMISIÓN TEXTUAL DE UNAS COPLAS DE JUAN DE MENA («SI GENTÍOS UNIVERSOS»)
}

\author{
Miguel Ángel Pérez Priego
}

UNED

Entre las piezas líricas de Juan de Mena, la que comienza con el verso «Si gentíos universos» es de las pocas de cierta extensión e importancia que se nos han transmitido en un único testimonio de la tradición diplomática. La composición (un decir amoroso de diez coplas reales de cuatro rimas y diez versos con alternancia de octosílabos y quebrados) no aparece recogida, en efecto, más que en el cancionero manuscrito de la Biblioteca Estense de Módena, ms. Alpha. R.8.9 (el cancionero MO o MEI, como se le suele identificar entre los estudiosos de la poesía castellana del siglo XV), fols. $47 v-48 v$, entre otros poemas de Mena y bajo la rúbrica «Joan de Mena, poeta prestantissimo". Atendiendo a ese único texto, ha sido editada modernamente por $\mathrm{G}$. Bertoni, por $\mathrm{A}$. Vàrvaro y por nosotros mismos'. Los más recientes y minuciosos catálogos de cancioneros, como el de J. Steúnou y L. Knapp o el de Brian Dutton y colaboradores, sólo dan cuenta igualmente de ese único testimonio ${ }^{2}$.

Lo que había pasado desapercibido hasta ahora es que ese mismo poema se halla también en otra muy conocida y frecuentada recopilación de materia poética de la época: el Cancionero de Palacio, ms. 617 (MPa, MP2), fols. $155 r-156 v$. Ocurre, sin embargo, que aqui el poema resulta dificilmente identificable, pues aparece bajo la rúbrica de «Obras de Castillo» y, para mayor confusión, con el añadido de dos nuevas coplas al comienzo del texto y una más como final, aparte de otra intercalada en el cuerpo del poema. Como los índices de cancioneros se hacen muchas veces atendiendo exclu-

1 G. Bertoni, "Catalogo dei codici spagnuoli della Biblioteca Estense di Modena", $R F$, XX (1907), pp. 366-68; A. Vàrvaro, Premesse ad un'edizione critica delle poesie minori di Juan de Mena. Nápoles, Liguori, 1964, pp. 126-130; Juan de Mena, Obra lirica, ed., introducción y notas de M. A. Pérez Priego, Madrid, 1979, pp. 119-123.

2 Jacqueline Stenou y Lothar Knapp, Bibliografia de los cancioneros castellanos del siglo XV y repertorio de sus géneros poéticos, París, 1975 y 1978; Brian Dutton, Catálogo-Indice de la Poesia Cancioneril del Siglo XV, Madison, 1982. 
sivamente a los primeros y últimos versos de los poemas, $\mathrm{y}$ apenas midiéndolos cuantitativamente con la vista, no es infrecuente que se produzcan este tipo de omisiones e inadvertencias. En nuestro caso, ni siquiera ha sido salvada por los autores de la última y más completa descripción del Cancionero de Palacio, ms. 617, quienes tampoco se han percatado de la relación del texto atribuido a Castillo con el de Mena ${ }^{3}$.

Ofrecemos a continuación ambas versiones del poema, cuya filiación creemos interesante tratar de dilucidar:

Si gentios universos cada qual por modos tanto diversos cantan en prosas e versos de su mal, diga yo, triste, cuitado, de mis penas, pues amores de buen grado me dan cuitas e cuidado por estrenas.
De las armas los guerreros, y del viento los valientes marineros, desputan los prisioneros de tormento; raçonan los labradores del arado, los viejos, los antigores, los caudillos y señores del estado.

Proponen los cavalleros de sus guerras, de tratos los escuderos, peregrinos $y$ estrangeros de las tierras; hablan los conquistadores de vitoria, de las leyes los doctores, y los buenos amadores de su gloria.

Si gentios universos cada qual por modos tanto diversos cantan en prosas y en versos de su mal, diga yo, triste, cuitado, de mis penas. pues amores de buen grado me dan cuitas y cuidado por estrenas.

3 José J. Labrador, C. Ángel Zorita y Ralph A. DiFranco, Cancionero de poesias varias (siglos XV y XVI), Biblioteca de Palacio, Ms. No. 617. Estudio preliminar, numeración y relación de poemas, indices, Cleveland State University-University of Denver, 1984, p. 62. 
Guerreando yo conmigo cada ora, pues con él batalfa sigo fablaré, triste, contigo, matadora, non de ninguno plazer(es) por ti dado(s), mas de cómo mi querer en amargo(s) desplazer es trocado.

Non pienses que por morir te desquiero, que tampoco mi vivir sin poderte bien servir non lo quiero, mas fazes mi mal ravioso ser tamaño que con fuego peligroso. mis ojos sin más reposo (h)amen daño.

Non sé quién te consejó tanto yerro nin qual causa te movió que de ti partiesse yo con destierro, que, si bien consideraras mi querer, nin a mi triste dexaras nin tampoco diffamaras tu valer.

Quieres que viva la vida con la muerte, mas non que muera vençida una ravi(os)a dolorida tanto fuerte; non te plaze que peresca nin que vivo, non consientes que padezca nin de tu nombre merezca ser captivo.

La cruda feroçidad de león
Guerreando yo comigo cada hora,

pues cruel batalla sigo, hablaré, triste, contigo, matadora, no de ningunos plazeres por ti dados, mas de cómo mis quereres en amargos desplaçeres son trocados.

Non pienses que por morir te desquiero, que tanpoco mi bivir sin poderte bien servir no lo quiero, mas hazes mi mal ravioso ser tamaño que con fuego peligroso mis ojos sin más reposo tienen daño.

No sé quién te aconsejó tanto yerro ni qual causa te movió que de ti partiese yo con destierro, que, si bien consideráis mi querer, ni a mi tan triste dexaras ni tanpoco disfamaras tu valer.

Tú hazes la piedad ser cuchillo, tratas contra charidad con el velo de bondad omeçillo; quieres que biva passión y destruyas los bienes de conpasión: ni sigues justa raçón ni la huyes.

Quieres que biva la vida con la muerte, mas no que muera vençida una ravia dolorida tanto fuerte; no te plaçe que padesca ni que biva, menos quieres que fenesca ni de tu nombre merésca ser captiva.

La ruda feroçidad del león 
do siente ser humildad subjuzga su bravedad a perdón;

pero tú, endureçida robadora, presumiendo ser temida, quieres ser más homiçida que señora.

Yo non [sé] cómo te diga nin comience, que nin ruego nin fatiga a ti, mortal enemiga, non convençe;

nin siento por qual manera te recuente

nin blasone comoquiera esta mi fuerte foguera $\tan$ ardiente.

Que si fuese en ti fallada solo un dia la clemençia denegada, non serás tú blasfemada nin seria en tal extremo venida mi salud que por ti fuesse perdida y del todo fenesçida la virtud.

Estonçes mi libertad se perdió quando tu gran crueldad cubierta de tal beldad se mostró, ca si yo te cognosçiera como agora nin yo triste me vidiera nin tampoco padesçiera cada ora.

Usurpas la condiçión de tus bienes, non miras por opinión al devido galardón que detienes; non me curo ya de $\mathrm{mi}$ çiertamente, mas conduélome de $t i$ que quieres perder assi tal serviente. adonde siente umildad sojuzga su bravedad a perdón;

pero tú de endureçida robadora, presumiendo ser temida, quieres ser más omiçida que señora.

Ya no sé cómo te diga ni comiençe, pues eres tal enemiga que ni ruego ni fatiga no te vençe; ni siento por qual manera te recuente ni blasone como quiera desta mi cruda hoguera tan ardiente.

Que si fuese en ti hallada solo un dia la clemençia denegada, no serías blasfemada ni sería en tal estremo venida mi salud que por ti fuese perdida y del todo feneçida la virtud.

Entonzes mi livertad se perdió quando tu gran crueldad cubierta de tal beldad se mostró, que si yo te conoçiera como agora nunca más triste me viera ni con tal pena muriera cadagora.

Usurpas la condiçión de tus bienes, no miras por opinión al devido galardón que detienes; no me curo ya de mi ciertamente, más conduélome de $\mathrm{ti}$ que quieres perder ansi tal sirviente. 


\author{
Si por tuyo le tubieras, \\ estimada \\ no dudes que sienpre fueras, \\ y si bien mirar quisieras, \\ más loada; \\ mas tú heres un caudillo \\ tan cruel \\ que ya no me maravillo \\ que destruyas un castillo \\ $\tan$ fiel.
}

Como se advierte, son notables las diferencias entre ambas versiones. La de $M P a$ se presenta, en apariencia, más completa y definitiva, lo que no quiere decir, sin embargo, que sea superior a la de MO. Ésta, a pesar de su más reducida extensión, no es un poema fragmentario, sino de completa unidad de sentido y acabada arquitectura formal: comienza con una construcción condicional de valor absoluto y se cierra -como muchas veces ocurre en los decires de la época- sin una finida expresa, función que, por otra parte, asume perfectamente la última copla del poema que contiene incluso el desplante imprecatorio del poeta. En cuanto al texto mismo, es claro que $\mathrm{MPa}$ ofrece una versión más modernizada, en la que se han eliminado no pocos arcaismos (consejo > aconsejo, do > adonde, blasonar $>$ blasonar de, non convençe > non te vençe, estonçes > entonzes, ca > que, vidiera $>$ viera que lleva a retocar todo el verso al perder una sílaba, etc.) y, lo que es más llamativo, en la que se han trivializado algunas expresiones y giros muy menianos (cruda ferocidad > ruda ferocidad; a $t i$, mortal enemiga $>$ pues eres tal enemiga, mi fuerte foguera $>$ mi cruda foguera; no te plaze que peresca I nin que vivo > no te plaçe que padesca / ni que biva con eliminación de la antítesis muerte-vida, perecer-vivir, muy característica de la lírica de amores meniana) ${ }^{4}$.

Estas mínimas consideraciones llevan, pues, a descartar la superioridad y autenticidad de $M P a$ respecto de $M O$. En consecuencia, creemos que este nuevo testimonio resulta insuficiente para despojar a Juan de Mena de la autoria del poema, frente a la segura atribución de $M O$-cancionero muy fidedigno en sus atribuciones y que recoge nada menos que dieciséis de Juan de Mena, todas ciertas - y frente a sus características internas de tema y estilo perfectamente acordes con el resto de la lírica amorosa de nuestro poeta.

La versión de $M P a$, por tanto, no puede ser considerada sino como una reelaboración del poema ya conocido de Juan de Mena, seguramente a partir de una copia del original distinta de la de $M O$. La reelaboración, como reza la rúbrica, es obra de Castillo, quien asimismo se nombra veladamente

${ }^{4}$ Comp., por ejemplo, el poema «A ti, sola turbación... / a ti, querida enemiga, / postrimer fin de mi mal", Juan de Mena, Obra lirica, ed. cit., núm. 12, p. 62. 
en la estrofa final: «que ya no me maravillo / que destruyas un Castillo / tan fiel». Se trata, sin duda, de Diego del Castillo, poeta de mediados del siglo $X V$ y de más bien escasa representación en los cancioneros de la época ${ }^{5}$. Sus composiciones nos lo sitúan en una primera etapa en la corte napolitana de Alfonso $\mathrm{V}$, a cuya muerte en 1458 compuso una Visión sobre la muerte del rey don Alfonso, y luego, tras su regreso a España, integrado en el grupo de poetas que se formó en torno a Gómez Manrique (con él intercambió algunos versos, $y$ varios de sus poemas se recogen precisamente en el cancionero de Pero Guillén de Segovia, muy representativo de ese grupo poético) ${ }^{6}$. Entre aquellos poetas, como se sabe, fue intenso el magisterio de Mena ( $\mathrm{Pe}$ ro Guillén se dice expresamente "discípulo suyo»), cuyos poemas fueron con frecuencia imitados y hasta continuados y reelaborados ${ }^{7}$. Diego del Castillo, conforme revela su corta obra, fue uno de los más decididos seguidores del poeta cordobés, a quien imitó tanto en el diseño del poema alegórico en arte mayor (Visión), como en sus composiciones amorosas. El tono reflexivo y patético de la queja amorosa, así como la preferencia por el decir largo y, sobre todo, la ostentación del propio nombre en los desplantes imprecatorios («pero más me maravillo / por ser vos un tal caudillo / de beldat qual parescéys, / que cruelmente matéis / vuestro Diego del Castillo») ${ }^{8}$, son rasgos que denuncian una clara influencia meniana en sus composiciones amorosas. En esas circunstancias, no parece raro que Castillo se decidiera en alguna ocasión a reelaborar e incluso a apropiarse de un poema de $\mathrm{Me}$ na que, por su particular comienzo («Si gentíos universos...»), le pareció incompleto o susceptible de complementar mediante la adición de dos estrofas enumerativas que explicitaran la referencia de ese abstracto y genérico "gentíos universos" con que se abría (aunque en realidad no logra una feliz adecuación de sentido y no hay una cabal correspondencia entre el canto de todas las gentes que dice Mena y la plática de los distintos personajes que enumera Castillo) y de una estrofa de finida con que rubrica y se adjudica la composición.

5 Véase ahora N. Salvador Miguel, La poesia cancioneril. El "Cancionero de Estuñiga", Madrid, 1977, pp. 73-76. Varias de sus composiciones fueron publicadas por R. Foulché-Delbosc, Cancionero castellano del siglo XV, 11, Madrid, 1915, pp. 215-228. 6-32.

6 Cfr. John G. Cummins, "Pero Guillén de Segovia y el Ms. 4114», HR. 41 (1973), págs.

7 Recuérdese, por ejemplo, que Pero Guillén y el propio Gómez Manrique emprendieron sendas continuaciones de las Coplas de los pecados mortales.

8 Cancionero castellano, ed. cit., núm. 460; el mismo motivo se localiza también en la núm. 459: «e quiera que vos, matando / con vuestro mortal cochillo, / persigáys nunca cessando, / nin de muerte perdonando / vuestro Diego del Castillo". 